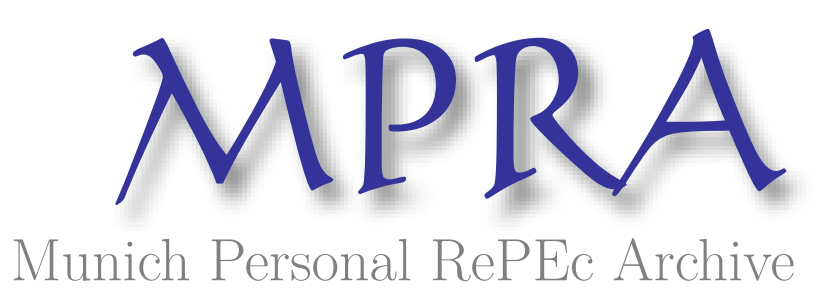

Farm Income, Population, and Farmland
Prices: A Relative Information Approach

Salois, Matthew and Moss, Charles and Erickson, Kenneth

University of Reading

25 October 2010

Online at https://mpra.ub.uni-muenchen.de/26848/

MPRA Paper No. 26848, posted 19 Nov 2010 17:40 UTC 


\title{
Farm Income, Population, and Farmland Prices: A Relative Information Approach
}

\author{
By Matthew J. Salois, Charles B. Moss, and Kenneth W. Erickson*
}

October 2010

\begin{abstract}
This paper uses an entropy-based information approach to determine if farmland values are more closely associated with urban pressure or farm income. The basic question is: how much information on changes in farm real estate values is contained in changes in population versus changes in returns to production agriculture? Results suggest population is informative, but changes in farmland values are more strongly associated with changes in the distribution of returns. However, this relationship is not true for every region nor does it hold over time, as for some regions changes in population are more informative. Results have policy implications for both equity and efficiency.
\end{abstract}

Keywords: entropy, land values, information theory, population.

JEL Classification: C11, C61, Q24.

* Correspondence to: Dr. Matthew J. Salois, Department of Agricultural and Food Economics, University of Reading, PO Box 237, Reading RG6 6AR, United Kingdom. Phone: +44 (0)118 378 7702. Fax: +44 (0)118 935 2421. Email: m.j.salois@reading.ac.uk. Matthew J. Salois is a Research Fellow in the Department of Agricultural and Food Economics at the University of Reading, UK. Charles B. Moss is a Professor in the Food and Resource Economics Department at the University of Florida, USA. Kenneth W. Erickson is an economist with the Economic Research Service, U.S. Department of Agriculture, USA. 


\title{
Farm Income, Population, and Farmland Prices: A Relative Information Approach
}

\author{
October 2010
}

\begin{abstract}
This paper uses an entropy-based information approach to determine if farmland values are more closely associated with urban pressure or farm income. The basic question is: how much information on changes in farm real estate values is contained in changes in population versus changes in returns to production agriculture? Results suggest population is informative, but changes in farmland values are more strongly associated with changes in the distribution of returns. However, this relationship is not true for every region nor does it hold over time, as for some regions changes in population are more informative. Results have policy implications for both equity and efficiency.
\end{abstract}

Keywords: entropy, land values, information theory, population.

JEL Classification: C11, C61, Q24. 


\section{Introduction and Background}

Many studies focus on the linkage between profitability and farmland values by analyzing the impact of farm income on farmland values (Alston 1986; Burt 1986). Other factors, such as population growth and urban pressure, have become increasingly important determinants of farmland values since the introduction of the New Deal farm programs and the acceleration of growth of urban and suburban areas. At the most basic level, increased urban pressure bids land out of agriculture because the return to agriculture cannot compete with the return to urban uses (Shi, Phipps, Colyer 1997). Indeed, Alfred Marshall was amongst the first to describe a relationship between agricultural land prices and population growth (Marshall 1907, p. 442). Marshall reasoned that as the population level increased, demands for agricultural goods would increase leading to greater demand for agricultural land, hence driving up the price of land, which is a fixed asset. At the core, Marshall was simply agreeing with the Malthusian notion of population growth. However, the increases in urban and suburban areas also increase the profitability of agriculture as producers shift to higher valued output (Livanis et al. 2006).

Factors affecting farmland values have significant consequences for a variety of groups. Given that farmland is the dominant asset in the agricultural balance sheet, factors affecting farmland values have significant implications for the opportunity cost of agricultural production. Changes in farmland values imply changes in farmer wealth which may affect the well-being of farm households. Extending beyond the farm gate, the use of farmland as collateral for farm loans links the financial viability of many rural lenders to farmland values. The rural financial crisis of the mid 1980s demonstrated the dependency of rural banks and the Farm Credit System on farmland values. Farm-

land values also contribute to the U.S. gross national product since they represent the principal real estate investment in the United States by area (Newell and Eves 2007). 
Comparing the effect of farm income and population growth on farmland values can be developed by examing the land valuation models of David Ricardo and Johann Heinrich von Thünen. Ricardo's model of farmland values is based on rents or the return to the "indestructible characteristics" of a particular plot of land. This rent is then defined by the differential productivity of the land given that all variable factors of production have been paid. In Ricardo's model, the most productive farmland only earns rent after the total demand for output exceeds the quantity of output that can be produced from the best quality of land. Specifically, once slightly less productive land is brought into production, the highest quality of land earns a rent equal to the difference in output. Von Thünen's model is of the same overall design, but considers the fact that distance to an urban center is also an indestructible characteristic of farmland determining its profitability. Von Thünen's model posits that land is used to produce commodities based on their value and the distance to the urban center. In the simplest model land close to the city center is dedicated to the crop with the highest transportation cost. At the margin the profit from its production (i.e., the value in excess of all other costs of production) is equal to the profit net of transportation cost of the next most expensive crop to transport. In this case the Ricardian rent is a decreasing function of the distance to the urban center. Given that farmland can be allocated to urban uses, the von Thünen model also explains several facets of the conversion of farmland to urban uses. Specifically, land closer to the urban center is more valuable for conversion than more distant parcels because of the increased expense of commerce and the cost of commuting to the workplace. Some of this value may be offset by the reduction in amenities such as green spaces.

The scope of public policy in agricultural land markets depends on a more intricate understanding of the effect of farm income and urban pressure. While not perfect, some of the most important features can be posited within the context of Ricardo versus von 
Thünen. If income is the salient factor in determining the value of farm real estate, then government payments which increase the expected return (or reduce the variance of returns) will be effective in supporting land values and maintaining farmer wealth. However, if urban pressure is more important then policies geared towards stimulating off-farm employment and generating urban growth will be more effective in maintaining farmer wealth. The policy problem is not only one of efficiency (how are public funds best directed towards improving wealth?), but one of equity (whose wealth is being enhanced or reduced?). The actual policy response is critical not just for the solvency of the agricultural sector, but increasingly for the performance of real estate investment portfolios and national economic growth.

This paper uses an entropy-based information approach to decompose the spatial and temporal variations in farmland values between changes in agricultural profitability and urban growth. In addition to contributing to the literature on factors affecting farmland values, this paper also provides a quantitative contribution by extending the standard use of entropy measures. The entropy metric is generalized to be a function of a compound prior formulated as a convex combination of base priors. The generalization permits for the derivation of an optimization problem to reveal which prior contains more relative information on the posterior distribution. Specifically, the compound prior defined in this paper is a convex combination of the shares of information contributed by both farm returns (net value added) and urban pressure (population). The value of the weighting parameter used in the convex combination of the base priors and solved in the optimization problem determines which prior is relatively more informative. The outcome of the optimization problem can be interpreted as a direct empirical test of the importance of farm income and urban sprawl in explaining farmland values. Entropy offers a robust interpretation of how much information on changes in farm real estate values is contained in changes in population versus changes in re- 
turns to farm production agriculture. Traditional measure of statistical association, such as simple test statistics and correlations, are convenient in that they function on the basis of linear relations involving continuous variables and/or Gaussian processes. If any of these conveniences fail, however, results from such measures can be misleading. Moreover, residuals from regression models can suffer from a variety of statistical complexities including non-linearity, heterogeneity, spatial auto-correlation, and serial dependence for any number of different reasons, such as misspecification of functional form or incorrect specification of expectations. Entropy measures are robust towards unknown non-linearities and non-Gaussian processes (Granger, Massoumi, and Racine 2004, p. 650).

The results are important since they suggest that while population is informative, changes in farmland values are more strongly associated with changes in returns to farmland. However, this relationship is not true for every region nor does it hold over time, as for some regions farm real estate values are more closely associated with changes in population. Hence, policies directed towards building wealth in the farm real estate market will have differential impacts, depending upon the region affected by the policy. An introduction to information theory and entropy methods is provided in section 2, followed by an application to farm real estate, and concludes with the derivation of the relative information approach. Then, section 3 describes the data and offers a basic descriptive analysis of the trends and fluctuations in farm real estate values and farm returns. In section 4 the empirical results are discussed and interpretations are offered. The final section concludes with particular attention to farm policy issues. 


\section{Information Theory and Entropy Model}

Information theory, originating with Shannon (1948), brought a technical and precise definition of information to the field of statistics. The technical notion of information states that outcomes conflicting with prior expectations should be given more weight than outcomes conforming to prior expectations. Shannon (1948) popularized the notion of entropy as the expected information from a distribution, and developed a quantified measure of information. More generally, entropy measures the uncertainty or volatility of a random variable or distribution (Maasoumi 1993). Kullback-Leibler (1951) generalize the Shannon-entropy and develop a relative entropy, or cross-entropy, metric that measures how two distributions differ from each other. ${ }^{1}$ Specifically, the cross-entropy metric measures the discrepancy or inequality between two distributions. The cross-entropy metric is often often referred to as a measure of information inequality, which can be interpreted as a measure of the difference of information content between distributions (Soofi 1994; Soofi 2000). Early applications of the information approach in the economics literature focused on the ability of the entropy measure to forecast distributions (Theil 1965, 1967; Tilanus and Theil 1965; Uribe et al. 1966). Theil (1979, 1989) popularized the information approach in economics using crossentropy to explain income inequality.

The cross-entropy measure is used in this paper to analyze whether the distribution of farm real estate values more closely follows the distribution of population or returns. The cross-entropy measure is not intended to infer causality between popula-

\footnotetext{
${ }^{1}$ Many generalizations of Shannon entropy exist, but the Kullback-Leibler function provides a meaningful information quantity that serves as the basis of the empirical application in this paper (Soofi and Retzer 2002).
} 
tion or returns on farm real estate values, though such causality may exist. Rather, the information approach is intended to measure how closely related are the distributions of farm real estate values, population, and returns. Measures of the relationship or association between distributions are important in economic forecasting and prediction (Granger, Maasoumi, and Racine 2004). In the particular application for farm real estate values, one interpretation of the cross-entropy measure is an evaluation of how well the distribution of population or returns forecasts farm real estate values. The cross-entropy metric can be computed first using population as the prior distribution and then again using returns as the prior distribution. The values of the two sets of information inequalities can then be compared to determine which factor contains more information. The information inequality with the smallest value implies a prior that has more information content. Alternatively, the entropy metric can be generalized to be a function of a compound prior formulated as a convex combination of multiple base priors. By weighting the informational content of each base prior distribution through a single parameter, an optimization problem reveals which prior contains more relative information on the posterior distribution.

Define the share of state population in a given year as $p_{i t}$, and the share of state farm real estate values in a given year as $v_{s t}$, where $s=1, \ldots S$ indicates the number of states and $t=1, \ldots, T$ indicates the number of years. Since the population shares and the farm real estate value shares are non-negative and add up to one, they satisfy the properties of a probability and so the cross-entropy metric can be used to measure the amount of information contained in each state's population on farm real estate values. Specifically, since $p_{s t}$ and $v_{s t}$ are the population and farm real estate value shares, respectively, then

$$
p_{s t}=\frac{P_{s t}}{\sum_{s}^{S} P_{s t}},
$$


where $P_{s t}$ is the population level in the $s^{t h}$ state in year $t$ and $\sum_{s}^{S} P_{s t}$ is the total population level in all $S$ states in a given year. Similarly

$$
v_{s t}=\frac{V_{s t}}{\sum_{s}^{S} V_{s t}}
$$

where $V_{s t}$ is the value of farm real estate in the $s^{t h}$ state in year $t$ and $\sum_{s}^{S} V_{s t}$ is the total value of farm real estate in all $S$ states in a given year. The total value of farm real estate is given by $V_{s t}=a_{s t} \cdot l_{s t}$ where $a_{s t}$ indicates the total acres of farmland and $l_{s t}$ is the per acre value of farm real estate in a given state in a particular year.

The cross-entropy metric, defined as $J(v: p)$, measures the discrepancy between the distribution of farm real estate values and the distribution of the population, or more succinctly, $J(v: p)$ measures the expected information of the message that transforms population shares into farm real estate value shares and is given by

$$
J(v: p)=\sum_{s=1}^{S} v_{i t} \ln \left(\frac{v_{s t}}{p_{s t}}\right)
$$

The measure $J(v: p)$ is a $t \times 1$ vector of information inequalities containing the informational content of population growth in explaining farm real estate values over years. If farm real estate values are perfectly proportional to population, the information inequality reaches a minimum of zero. If farm real estate values are not perfectly proportional, then information exists and the information inequality becomes positive. The information inequality in equation 1 gives a measure of the variation in farm real estate values not explained by variation in population. This unexplained variation may be attributed to variation in other factors, such as farm returns, or some other contributing factor (e.g., interest rates, government subsidies, etc.).

In order to infer the relative significance of regional variation in population on farm real estate values, the decomposition property of the information inequality is used. 
States can be grouped by geographic region, allowing the information measure to be computed based on within-group and between-group comparisons. Define the region $R_{g}$ where $g=1, \ldots, G$ for the $g^{t h}$ region of states so that each state belongs to exactly one region. The population share is $P_{g t}$ and the farm real estate value share is $V_{g t}$ for the $g^{\text {th }}$ region where

$$
P_{g t}=\sum_{s \in R_{g}} p_{s t}
$$

and

$$
V_{g t}=\sum_{s \in R_{g}} v_{s t}
$$

Further define $\zeta_{s t}$ as the share for the $s^{t h}$ state in the population of the region to which it belongs and similarly define $\eta_{s t}$ for the regional farm real estate value share, then

$$
\zeta_{s t}=\frac{p_{s t}}{P_{g t}}
$$

and

$$
\eta_{s t}=\frac{v_{s t}}{V_{g t}}
$$

where $s \in R_{g}$ and $g=1, \ldots, G$. The within-region inequality is given by

$$
J_{g}(v: p)=\sum_{s \in R_{g}} \eta_{s t} \frac{\eta_{s t}}{\zeta_{s t}}
$$

The between-region information inequality is given by

$$
J_{R}(v: p)=\sum_{g=1}^{G} V_{g t} \ln \left(\frac{V_{g t}}{P_{g t}}\right)
$$

The total information inequality is then the sum of the between-region inequality and 
the average within-region inequality

$$
J(v: p)=J_{R}(v: p)+\sum_{g=1}^{G} V_{g t} J_{g}(v: p) .
$$

The within-region measure, $J_{g}$, is the regional variation in farm real estate values not explained by population changes in region $g$. The between-region measure, $J_{R}$, is the information inequality between the $G$ regions, and reflects the contribution of inequality due to differences in individual region means. The average within-region measure is a simple weighted sum of the within-region inequality values.

The information inequality and the regional decomposition above is similarly defined by using farm return shares in place of population shares as the prior distribution. For example, if the annual share of state farm returns is defined by $y_{i t}$ then the information inequality using farm returns as the prior is given by

$$
J(v: y)=\sum_{s=1}^{S} v_{i t} \ln \left(\frac{v_{s t}}{y_{s t}}\right)
$$

which has the same interpretation as the population prior information inequality, but is based on returns to farmland.

While the empirical method outlined above provides an informational measure on the individual importance of population and farm returns on farm real estate values, it does not provide a measure of the relative importance of either factor. This is critical to answering the question, "how much information on changes in farm real estate values is contained in changes in the population versus changes in returns to agriculture?" What is needed to answer this question is a measure of the relative information provided by multiple prior distributions on a particular posterior distribution. An approach is needed to determine which factor provides more relative information on farm real estate values. 
The problem is similar to the issue in Bayesian econometrics of finding non-informative priors when wide disagreement exists regarding the choice of prior. Techniques developed in the Bayesian econometrics literature are aimed at finding non-informative priors. Jaynes (1957) introduced the maximum entropy principle and is based on Shannon's entropy measure, which fundamentally states the least informative prior can be found by maximizing the entropy over a set of prior probability distributions. A related idea is based on maximizing the expected Kullback-Leibler cross-entropy measure; since cross-entropy increases in value when the prior and posterior distributions are more divergent, then the greater the cross-entropy the more non-informative the prior distribution is on the posterior distribution (Bernardo and Ramon, 1998). However, the problem at hand in the current paper is in some ways the mirror image of the noninformative prior problem in Bayesian econometrics. The key question is: what is more informative on farm real estate values, population or farm returns? In this context, the search is for the prior distribution (i.e., population or returns) that is the least divergent from the posterior distribution (i.e., farm real estate values). While the search for non-informative priors involves entropy-maximization, the approach developed in this paper involves entropy-minimization.

Finding the exact least-informative prior using the Kullback-Leibler cross-entropy is generally considered an intractable problem for finite samples, involving an infinitely dimensional optimization problem. Spall and Hill (1990) develop an innovative technique for determining least-informative priors by constraining a set of prior distributions as an optimal convex combination. Their method is used here, but is adapted to involve minimization of the cross-entropy measure rather than maximization. Let $x_{1}, \ldots, x_{k}$ be the set of $k$ priors. The goal is to find from this set the prior that diverges in distribution from the posterior $y$ the least (i.e., is the most informative). Let $\Phi=\left(\phi_{1}, \ldots, \phi_{k-1}\right)^{\prime}$ 
be the set of weighting parameters that satisfy the following conditions

$$
\sum_{j=1}^{k-1} \phi_{j} \leq 1, \phi_{j} \geq 0
$$

By solving $\phi_{k}=1-\sum_{j=1}^{k-1} \phi_{j}$, each $\phi_{k}$ is uniquely determined. The optimal convex combination of priors, $z^{\star}$, is found by solving

$$
J\left(y: z^{\star}\right)=\min _{\phi \in \Phi}\left\{J(y: z): z=\sum_{j=1}^{k} \phi_{j} x_{j}\right\}
$$

The new prior given by $z=\sum_{j=1}^{k} \phi_{j} x_{j}$ is defined as the compound prior. The minimization problem in equation 7 finds the values of $\phi_{j}$ that result in the convex combination of priors yielding the smallest value of the information inequality. Spall and Hill (1990) show that $J\left(y: z^{\star}\right)$ is a strictly concave function of $\phi_{j}$ for the optimization problem, which guarantees uniqueness of the optimum and permits the use of numerical algorithms to find the unique solution. The optimal weighting parameters, $\phi_{j}^{\star}$, are interpreted as the relative information content of the prior distributions. The concept can be thought of as a mapping of information sets; the weighting parameter measures how much information is coming from each set.

To illustrate this approach for the case of the farm real estate value information inequality, the compound prior is defined as a convex combination of the population shares and the farm returns shares so that $z=\phi \cdot p+(1-\phi) \cdot y$, which can be interpreted as a weighted average of the two priors. The optimal combination of the population prior and the returns prior is then found by minimizing

$$
J\left(v: z^{\star}\right)=\min _{\phi}\left\{\sum_{s=1}^{S} v_{i t} \ln \left(\frac{v_{s t}}{z_{s t}}\right): z=\phi \cdot p+(1-\phi) \cdot y\right\} .
$$

The new optimal compound share is the convex combination of $p$ and $y$ obtained with 
the optimal $\phi^{\star}$ found from the minimization problem. The value of $\phi^{\star}$ provides an interesting measure of the relative importance of population versus returns in explaining farm real estate values. As $\phi^{\star} \rightarrow 0$, returns to agriculture do a better job explaining the distribution of farm real estate values. However, as $\phi^{\star} \rightarrow 1$, population does a better job explaining farm real estate values . Given decomposability, the weighting parameter can be calculated for each region. Thus, the value of $\phi^{\star}$, can be interpreted as a direct empirical test of the importance of farm income and urban sprawl in explaining farmland values. Entropy offers a robust interpretation of the relationship between farmland values with population and farm income. Further, the sample can be split into distinct time periods to see how, and if, the influence of population and farm returns has changed over time.

\section{Data and Descriptive Analysis}

The primary agricultural data are found in the National Agriculture Statistics Service (NASS) of the U.S. Department of Agriculture. Farm real estate values are obtained from the Agricultural Land Values and Cash Rents publication. Land in farms are obtained from the Farms, Land in Farms, and Livestock publication. Population estimates are obtained from the U.S. Census Bureau. The data cover the 1950 - 2008 time frame. Farm real estate values are defined as the per acre dollar value of all land and buildings used for agricultural production. Land in farms is defined as the total acres of farmland, in thousands of acres, for each state. The total value of farm real estate is computed by multiplying the per acre dollar real estate value by the total number of acres of farmland for each state. Net value added is used in place of the more traditional net farm income for describing returns to agriculture. Net value added (NVA) includes 
the net returns to all equity and non-equity holders and thus represents agriculture's contribution to the overall economic activity of the United States. As defined by the Economic Research Service (ERS): "Net value added represents the total value of the farm sector's production of goods and services, less payments to other (nonfarm) sectors of the economy. It reflects production agriculture's addition to the National economic product. It also represents the sum of the economic returns to all the providers of factors of production; farm employees, lenders, landlords, and farm operators." Thus, NVA represents a more accurate indicator of the farm sector's total output of goods and services than farm income since NVA is a broader measure (Erickson et. al 2004). The regional definitions used to group the 48 coterminous states (excluding Alaska and Hawaii) are the ten farm production regions designated by the Economic Research Service $^{2}$. The population, net value added, and farm real estate values for the ten regions are in Table 1 for the years 1950 and 2008. The relative ranking of each region is indicated in parentheses to provide a regional comparison. The Northeast is consistently the most populous region, while the Southern Plains remain the least populous. In terms of net value added, particularly notable is the stark increase in magnitudes for the individual regions. Most regions saw at least a ten-fold increase in net value added between 1950 and 2008. The Corn Belt and Pacific regions saw the starkest increase in NVA over the time period. Figure 1 illustrates the annual increase in net value added for the ten ERS defined farm production regions. The steadily increasing trend since the early 1970s is apparent, as is the relative magnitude of the Corn Belt region compared to the other regions. Net value added for the Delta region

\footnotetext{
${ }^{2}$ In this study we use the traditional regions with the Northeastern states include Connecticut, Delaware, Maine, Maryland, Massachusetts, New Jersey, New York, Pennsylvania, Rhode Island, and Vermont, Lake States are Michigan, Minnesota, Wisconsin, the Corn Belt region includes Illinois, Indiana, Iowa, Missouri, and Ohio, the Appalachian region includes Kentucky, North Carolina, Tennessee, Virginia, and West Virginia, the Southeast states are Alabama, Florida, Georgia, and South Carolina, Delta States are Arkansas, Louisiana, and Mississippi, the Southern Plains states are Oklahoma and Texas, the Mountain region includes Arizona, Colorado, Idaho, Montana, New Mexico, Nevada, Utah, and Wyoming, and the Pacific states are California, Oregon, and Washington.
} 
remined the most flat over the time period.

The total value of farmland increased several orders of magnitude from 1950 to 2008. The Northeast, Southeast, and Delta regions consistently have the lowest total value of farmland compared to the other regions. The per acre value of farmland for the Northeast is the highest of any region, but since it has the least amount of land in farms, the total value is comparatively much smaller. The Corn Belt region is consistently the highest valued farmland region by a large margin. The high value of the Corn Belt is driven by both a large amount of land in farms and high per acre values. The remaining regions fluctuate in ranking between time periods. The Mountain region increased steadily in farmland value ranking moving from seventh to second, while the Northern Plains region fell from third to fifth. Like the pattern with net value added, the value of farm real estate saw large increases in the magnitude of real estate values, increasing several orders of magnitude in the time period considered. Total farm real estate values are graphed for each of the regions over the time period in Figure 2. The Corn Belt states clearly have the highest total farm real estate values. Following far behind the Corn Belt region are the Mountain, Pacific, and Southern Plain regions. The prominent boom-bust cycle that occurred in farmland values between the mid 1970s to mid 1980s is also seen in Figure 2.

\section{Results and Discussion}

First, population is examined as the prior distribution. The regional information inequality in equation 2 is used to compute the information content of population in explaining farm real estate values for each of the ten ERS defined regions. As the ratio in equation 2 approaches equality, the logarithm approaches zero. In this case 
real estate shares follow population shares more closely. However, as the information inequality becomes more positive, population shares contain less information on farm real estate values. For ease of interpretations, the results are presented graphically in Figure 3. For many of the regions (Appalachia, Pacific, Delta, Southeast, Northern Plains), the inequality is quite small over time and in fact is generally bounded by a small value (0.10). For these regions, the shares of farm real estate values and population have similar distributions. Notable exceptions include the Northeast, Corn Belt, Lake, and Mountain regions, which have higher inequality values. Interestingly, while the 2008 inequality value for the Lake region has changed very little from 1950, the inequality has fluctuated widely over time, having a cyclical appearance. The cycle is similar for the Corn Belt and Northeast regions, though all three have a clear upward trend to them. This indicates a fluctuating relationship between farm real estate values and population for these regions. The inequality for the Mountain region has increased nearly six-fold over the 1950 - 2008 time period, indicating the dispersion between farm real estate and population has increased, that is, their distributions have become more dissimilar. Overall, the results show that regional differences exist in the information content of population.

Figure 4 builds on the within-region inequalities by presenting the decomposition of the inequality between regions. The general overall dispersion between farm real estate and population has been rather stable over time with the total inequality in 2008 varying very little from the 1950 value. Between the early 1970s and the late 1980s, the overall dispersion in the total inequality increased and then began to decrease again, suggesting that the relationship between farm real estate and population diverged in that time frame. The pattern is also seen in the between-region and average withinregion inequality, though to a lesser extent. The within-region inequalities in Figure 3 suggest this pattern may have been driven by the Northeast, Corn Belt, and Lake 
region, which were heavily affected by the boom-bust cycle. The between-region and the average-within region inequalities have also changed very little over time, with the exception of the 1970 - 1985 time period. This suggests that the dispersion between farm real estate and population has been steady both between regions and in states within regions on average. This implies a stable relationship in the information content of population on farm real estate values. The value of the overall dispersion is mostly attributed to the between-region inequality since the between-region inequality has been generally more than $60 \%$ of the total inequality. This suggests that most of the dispersion between farm real estate values and population is due to the between-region variation. However, as seen in Figure 4, the percentage of total inequality that is between-region is declining.

Second, net value added is examined as the prior distribution. Figure 5 presents the within-region information inequalities using net value added as the prior distribution. Generally, the inequality values are quite small and similar across all regions, with a bound of less than 0.05 as an inequality value. The values are much smaller than the population information inequalities in Figure 3, indicating that net value added and farm real estate values follow one another more closely in distribution than population. The Appalachia and Mountain states are the notable exceptions. In the 1970s, the inequalities for the Appalachia and Mountain regions diverged from the remaining regions. The 2008 values of the inequalities are more than 10 times the magnitude of the 1950 values for both the Appalachia and Mountain regions. This suggests that since the 1970s, net value added has contributed less information to farm real estate for these two regions compared to the other regions. Figure 6 presents the decomposition of the inequalities. The general overall dispersion between farm real estate and net value added has been increasing over time from 1950 - 2008. This suggests that farm real estate and net value added have diverged in distribution over time. 
Results imply that while NVA remains more descriptive of farm real estate than population as given by the smaller inequality values, the information content of NVA has begun to break down. Moreover, the upward trend in the overall dispersion has not been a steady increase since the overall dispersion has fluctuated between ups and downs, as seen in Figure 6. This suggests that the relationship between farm real estate and NVA may be sensitive to other factors and so is not as stable as that between population and farm real estate. The between-region and average within-region inequalities have also increased over time. This implies that regions are becoming less alike and that states within regions are also becoming less alike in terms of net value added. The contribution to the overall dispersion between farm real estate and NVA is mostly attributed to the between-region inequality since the between-region inequality is more than $60 \%$ of the total inequality, at least until 1990. Since 1990, the betweenregion inequality is around $50 \%$ of the total inequality, suggesting the between-region and the average within-region variation in the dispersion between farm real estate and NVA contribute equally to the total variation.

Lastly, the information inequality is re-computed based on a new compound prior share defined as an optimal convex combination of the population and net value added shares. The solution to the minimization problem in equation 8 is obtained using the BFGS descent algorithm. The value of $\phi^{\star}$ from the minimization problem indicates the relative information content of each share. If $\phi^{\star}$ is closer to 1 , then population has more information content, if $\phi^{\star}$ is closer to 0 then net value added has more information content. This was done for the U.S. overall and for each individual farm region over three time periods $\left(1950-2008,1950-1979\right.$, and 1980-2008). The estimates of $\phi^{\star}$ for the U.S. and for each farm region over the three time periods are reported in Table 2.

Over the whole time period (1950-2008), generally $\phi^{\star}$ is closer to 0 than to 1 , suggesting that net value added and farm real estate values follow each other more closely 
in distribution than population and so NVA has more relative information content. The value of the weighting parameter is remarkably similar for the Delta, Mountain, Northern Plain, Southern Plain, and Pacific regions (between 0.26 and 0.35). This suggests that the relative association, or relative information content, of NVA with farm real estate values is about the same for these regions. There are, however, notable exceptions. For the Northeast region, the value of $\phi^{\star}$ is 0.06 which suggests that population contributes nearly no relative information content to changes in the distribution of farm real estate values for this region. For the Southeast region the value is 0.52 , suggesting both population and NVA contribute roughly equal information content to changes in the distribution of farm real estate. The value of $\phi$ for the Appalachia region is 0.66 , implying population is actually more informative than net value added. The large value of $\phi^{\star}$ for the Appalachia region is particularly interesting, given the strong upward trend in total farmland values for this region since 2002.

The optimization problem in equation 8 is re-computed for two distinct time periods (1950-1979 and 1980-2008). As can be seen by scanning over the values of $\phi^{\star}$ for each region between the two time periods, the relative information content of population and net value added is not static over time but in fact is changing over time, as evidenced by the shifting values. More importantly, the dynamic change in the relationship between farm real estate, population, and net value added differs by farm region. For the Pacific region, $\phi^{\star}$ was 0.08 for the $1950-1979$ time frame indicating that compared to NVA population was relatively uninformative. However, for the 1980-2008 period the value of $\phi^{\star}$ is 0.56 , suggesting that now population provides more relative information than net value added. The Appalachia region tells a similar story.

Conversely, before 1980, population was relatively more informative than NVA for farm real estate values in the Northern Plain and Southeast regions. Interestingly, this association shifted after 1980 with NVA being the more important factor. The 
importance of population has increased for the U.S. overall as $\phi^{\star}$ increased from 0.02 before 1980 to 0.13 for the years after 1980 . However, net value added remains far more informative than population in explaining U.S. farm real estate values overall. For some regions the relationship has not changed very much over time, which include the Northeast, Corn Belt, Mountain, Southern Plains, and Lake regions. While $\phi^{\star}$ differs in magnitudes for each of these regions, they are all less than 0.50 , suggesting that net value added is the more important factor than population in explaining farm real estate values.

Clearly, the distributional relationship of population and net value added with farm real estate values not only differs through time, but is variable between geographic regions as well. This relationship tends to shift in both strength and direction, depending on the time frame and region. While the actual causes of these shifts is an interesting empirical question itself (and outside the scope of this paper), the results have important policy implications. If the goal is to enhance wealth through the farm real estate market (benefiting both the agricultural sector and farmer wealth) a blanket public policy, such as stabilizing farm income via government payments, may be too blunt an instrument. Given the results for the Appalachia and Pacific regions (and to a lesser extent the Southeast region), the influence of population is relatively more important than farm income. Policies that generate urban growth and off-farm wealth may be more successful at stimulating increases in farm real estate values for these regions.

Results here demonstrate that the scope of public policy in the agricultural land market depends on which factor is the intended "tool" of public policy. If the policy is intended to increase farm wealth through government payments, then the benefits will accrue to farm real estate values through residual returns. Both "population" and "profits" can create resource rents, both in the short-run, and possibly in the longerterm. The entropy approach in this study determines whether changes farm real estate 
values are more associated with changes in profits or with changes in urban sprawl, over space and time. While population is informative, changes in farmland values overall are more strongly associated with changes in returns to farmland. But this is not the whole story. Since the results suggest that changes in the distribution of population are the more salient factor for farm real estate values in the Appalachia and Mountain regions, then policies directed towards promoting off-farm income and employment, and thereby stimulating urban growth, are more appropriate. That is, a blanket national policy will not likely be equally effective when applied to all farm regions. Rather, results here suggest farmland policies that are designed on a regional rather than a national basis.

\section{Conclusions}

This paper builds on the copious work on farmland values, focusing on the relative importance of urban pressure (as described by population) versus farm returns (as described by net value added). An information approach is used based on an entropy measure to assess the relative importance, or information content, of each factor to farm real estate values. Three contributions are offered by this paper. First, the paper contributes a relative information measure that generalizes the the standard information approach to be a function of multiple prior distributions. The generalization permits for the derivation of an optimization problem to reveal which factor (population or income) contains more relative information regarding the posterior distribution (real estate values). This approach offers both an insightful and intuitive comparison on whether farm real estate values are more closely associated with changes in the distribution of population or farm income.

Second, an important problem in the literature is addressed. Assessing the relative 
importance of population growth and farm income on farm real estate values has significant policy implications. Farmland values are important to key stakeholders such as farm operators, lenders, and non-operator landlords. For example, farmland values affect the relative prices of inputs, such as farm labor and borrowing costs, and thus the returns to labor and capital. Moreover, farmland values reflect the rental value of the land, which reflects the net rental income to non-operator landlords. In general, farmland values are crucial to the economic vitality of the agricultural sector. Not only is farm real estate a traditional source of wealth to farmers, but historically farmland values have served as a combination of both a retirement portfolio and an estate for bequest to future generations of farmers. In the vernacular of the rural community, a farmer lives poor and dies rich. Similarly, farm real estate has served as a collateral for farm mortgages, reducing the effect of capital costs for both expansion and operating credit (the farm credit crisis of the mid 1980s resulted largely from the loss of collateral from falling farmland values). From an even broader perspective, farm real estate values have implications for many environmental decisions. For example, increased farmland values reduce the rate of conversion of farmland into urban and other uses. Thus, in making agricultural policy choices, decisions are being made about environmental quality through the agricultural/urban conversion trade-off. Within this context, this paper examines factors that affect farm real estate values, focusing on the relationship with population growth and farm income.

Lastly, the results are important since they suggest that while population is informative, changes in the distribution of farm real estate values are more closely associated with changes in farm returns. Moreover, the information content of population and net value added is not static over time but in fact is a dynamic process. More importantly, the dynamic change in the relationship between farm real estate, population, and net value added differs by farm region. In the aggregate, overall national changes in farm- 
land values are more strongly associated with changes in returns to farmland (though population has become relatively more informative over time). However, the disaggregation of the relationship over both time and region reveals that this is not always the case. For some regions, population has become less informative (Lake, Northern Plains, Southeast, Delta Southern Plains) but more informative for others (Northeast, Corn Belt, Appalachia, Mountain, and Pacific). Additionally, while farm income seems to be the more predictive factor in most of the farm regions, population is more informative for the Appalachia region and more recently for the Mountain and Southeast regions. The scope of public policy in the agricultural land market depends on which factor the policy is intended to operate through. If the policy is intended to increase farm wealth through government payments, for example, then the benefits will accrue to farm real estate values through residual returns. However, this is not the whole story. Since the results suggest that changes in the distribution of population are the more salient factor for farm real estate values in the Appalachia and Mountain regions, then policies directed towards promoting off-farm income and employment, and thereby stimulating urban growth, are more appropriate. In other words, a blanket national agricultural policy may be too blunt an instrument to be effective towards promoting the vitality of the farm real estate market. 


\section{References}

[1] Alston, J.M. (1986) An analysis of growth of U.S. farmland prices, 1963-82. American Journal of Agricultural Economics, 68(1): 1-9.

[2] Bernardo, J.M., and J. M. Ramon. (1998). An introduction to Bayesian reference analysis: inference on the ratio of multinomial parameters. Journal of the Royal Statistical Society 47(1): 101-135.

[3] Burt, O.R. (1986) Econometric modeling of the capitalization formula for farmland prices. American Journal of Agricultural Economics, 68(1): 10-26.

[4] Erickson, K.W., S.C. Blank, C.B. Moss, and A.K. Mishra. (2004) Regional changes in the distribution of net value added in U.S. agriculture, 1960 - 2002. Selected Paper for the 2004 Western Agricultural Economics Association Annual Meeting, July 1 - 3, Honolulu, Hawaii.

[5] Granger, C.W., E. Maasoumi, and J. Racine. (2004) A dependence metric for possibly nonlinear processes. Journal of Time Series Analysis, 25(5): 649-669.

[6] Jaynes, E.T. (1957) Information theory and statistical mechanics II. Physical Review, 108(2): 171-190.

[7] Kullback S., and R.A. Liebler. (1951) On information and sufficiency. Annals of Mathematical Statistics, 22(1): 79-86.

[8] Livanis, G., C.B. Moss, V.E. Breneman, and R.F. Nehring. (2006) Urban sprawl and farmland prices. American Journal of Agricultural Economics, 88(4): 915-929.

[9] Maasoumi, E. (1993) A compendium to information theory in economics and econometrics. Econometric Reviews, 12(2): 137-181.

[10] Marshall, A. (1907) Principles of Economics, 5th Edition. Macmillan: London, UK.

[11] Newell, G., and C. Eves. (2007) The role of U.S. farmland in real estate portfolios. Journal of Real Estate Portfolio Management, 13(4): 317-327.

[12] Shannon, C.E. (1948) A mathematical theory of communication. Bell System Technical Journal, 27: 379-423; 623-656.

[13] Shi, Y.J., T.T Phipps, and D. Colyer. (1997). Agricultural land values under urbanizing influences. Land Economics, 73(1): 90-100.

[14] Soofi, E.S. (1994) Capturing the intangible concept of information. Journal of the American Statistical Association, 89(428): 1243-1254. 
[15] Soofi, E.S. (2000) Principle theoretic approaches. Journal of the American Statistical Association, 95(452): 1349-1353.

[16] Soofi, E.S., and J.J. Retzer. (2002) Information indices: unification and applications. Journal of Econometrics 107(1-2): 17-40.

[17] Spall, J.C, and S.D. Hill. (1990) Least-informative Bayesian prior distributions for finite samples based on information theory. IEEE Transactions on Automatic Control 35(5): 580-583.

[18] Theil, H. (1965) The information approach to demand analysis. Econometrica, $33(1): 67-87$.

[19] Theil, H. (1967) Economics and Information Theory. Elsevier Publishing Company, New York, NY.

[20] Theil, H. (1979) World income inequality and its components. Economics Letters, 2(1): 99-102.

[21] Theil, H. (1989) The development of international inequality: 1960-1985. Journal of Econometrics, 42(1): 145-155.

[22] Tilanus, C.B., and H. Theil. (1965) The information approach to the evaluation of input-output forecasts. Econometrica, 33(4): 847-862.

[23] Uribe, P., C.G. de Leeuw, and H. Theil. (1966) The information approach to the prediction of inter-regional trade flows. Review of Economic Studies, 33(3): 209220. 
Table 1: Population, net value added, and farm real estate values (selected years)

\begin{tabular}{|c|c|c|c|c|c|c|}
\hline & \multicolumn{2}{|c|}{$\begin{array}{c}\text { Annual Population } \\
\text { (thousands of people) }\end{array}$} & \multicolumn{2}{|c|}{$\begin{array}{l}\text { Net Value Added } \\
\text { (millions of dollars) }\end{array}$} & \multicolumn{2}{|c|}{$\begin{array}{l}\text { Total Farmland Value } \\
\text { (millions of dollars) }\end{array}$} \\
\hline & 1950 & 2008 & 1950 & 2008 & 1950 & 2008 \\
\hline $\mathrm{NE}$ & (1) 42,236 & (1) 61,431 & 934 & (10) 7,038 & $\begin{array}{ll}(8) & 5,652\end{array}$ & (9) 110,424 \\
\hline $\mathrm{LS}$ & (5) 12,842 & (8) 20,852 & (4) 1,197 & (4) 14,994 & (6) 6,670 & (6) 177,413 \\
\hline $\mathrm{CB}$ & (2) 27,274 & (3) 39,678 & (1) 3,111 & (1) 30,428 & (1) 19,155 & (1) 426,633 \\
\hline NP & (10) 4,517 & (10) 6,031 & (2) 1,522 & (3) 18,771 & (3) 8,770 & (5) 178,468 \\
\hline AS & (3) 15,640 & (5) 29,290 & (3) 1,493 & (7) 8,025 & 6,902 & (7) 165,025 \\
\hline $\mathrm{SE}$ & (6) 11,439 & (4) 37,156 & (7) 1,017 & (6) 9,978 & 4,001 & (8) 131,930 \\
\hline $\mathrm{DS}$ & (8) 6,781 & (9) 10,205 & (10) 824 & (9) 7,282 & (10) 3,280 & (10) 72,537 \\
\hline $\mathrm{SP}$ & (7) 10,005 & (6) 27,969 & (6) 1,092 & (8) 7,666 & 8,813 & (3) 242,485 \\
\hline MS & (9) 5,101 & (7) 21,785 & 860 & (5) 10,121 & 5,862 & (2) 275,356 \\
\hline PS & (4) 14,596 & (2) 47,096 & (5) 1,175 & (2) 21,277 & 8,565 & (4) 224,632 \\
\hline
\end{tabular}

Table 2: Optimal weighting parameter values for within-region inequalities (compound prior)

\begin{tabular}{cccccccccccc}
\hline Time / Region & U.S. & NE & LS & CB & NP & AS & SE & DS & SP & MS & PS \\
\hline $1950-2008$ & 0.07 & 0.06 & 0.14 & 0.19 & 0.35 & 0.66 & 0.52 & 0.26 & 0.31 & 0.27 & 0.34 \\
$1950-1979$ & 0.02 & 0.05 & 0.16 & 0.16 & 0.54 & 0.48 & 0.79 & 0.27 & 0.33 & 0.25 & 0.08 \\
$1980-2008$ & 0.13 & 0.07 & 0.11 & 0.22 & 0.20 & 0.79 & 0.47 & 0.25 & 0.30 & 0.29 & 0.56 \\
\hline
\end{tabular}


Figure 1: Net value added by farm region, 1950 - 2008 (in millions of dollars)

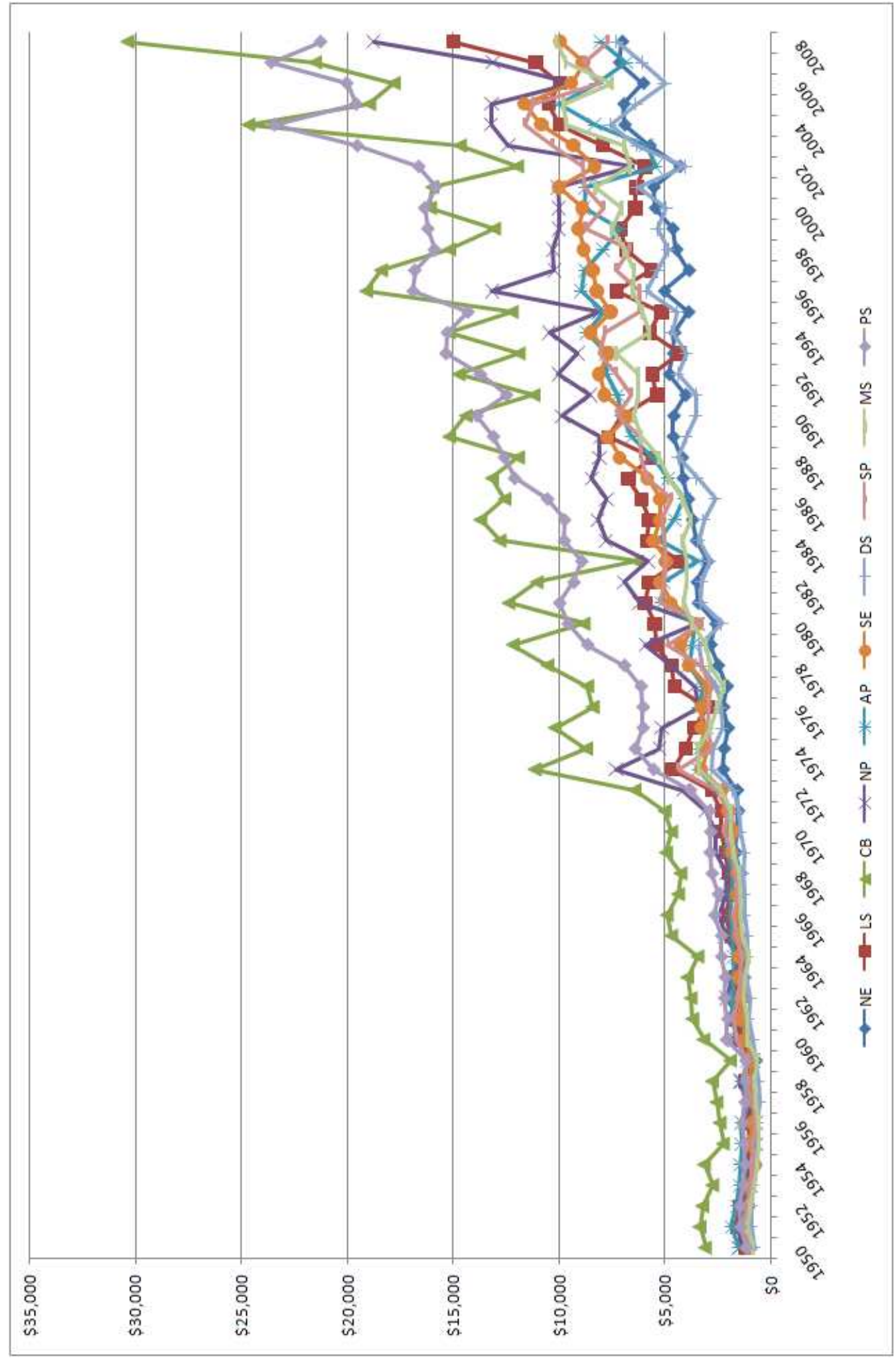


Figure 2: Total farm real estate values by farm region, 1950 - 2008 (in millions of dollars)

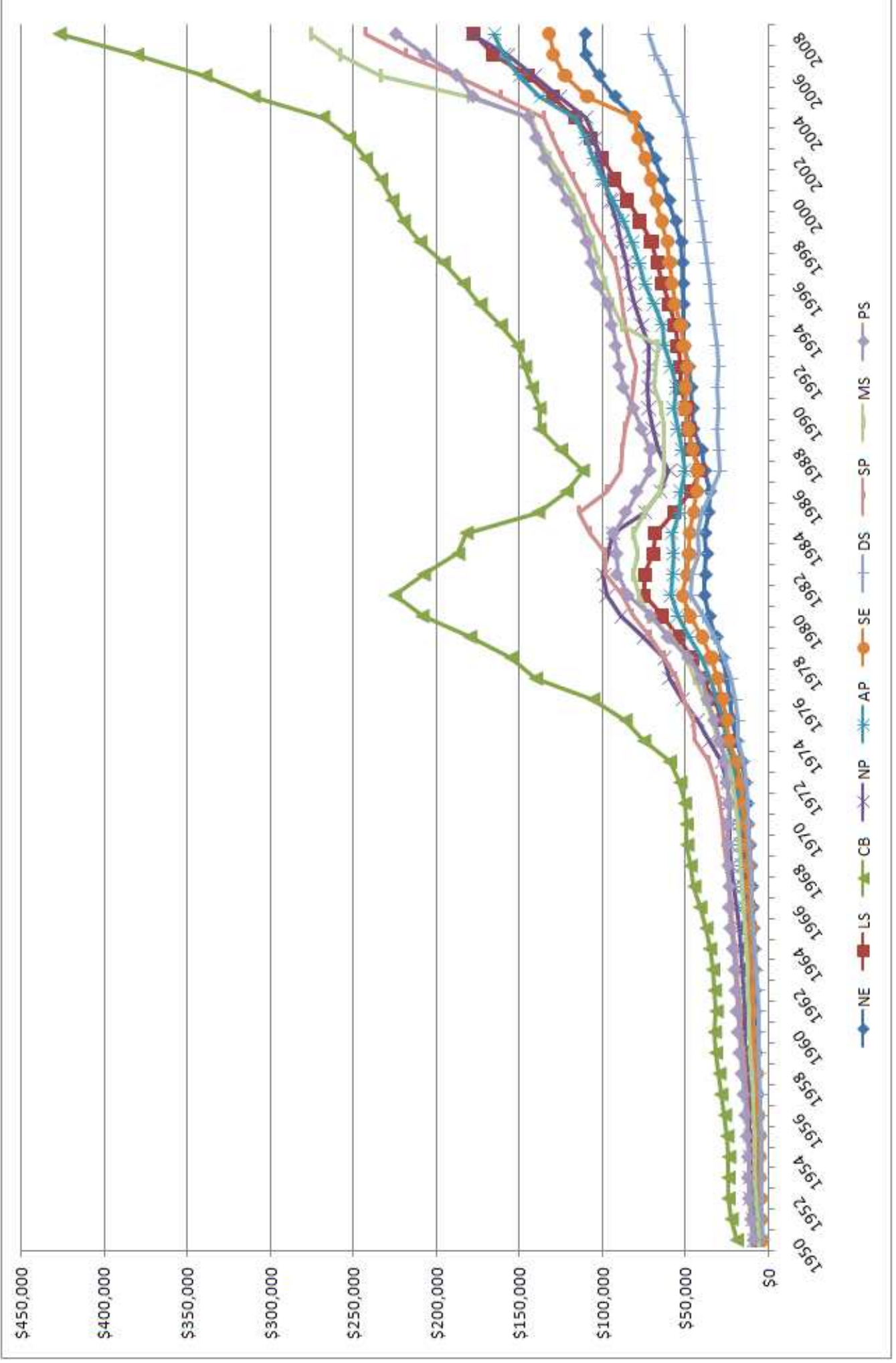


Figure 3: Information inequality within regions (population prior)

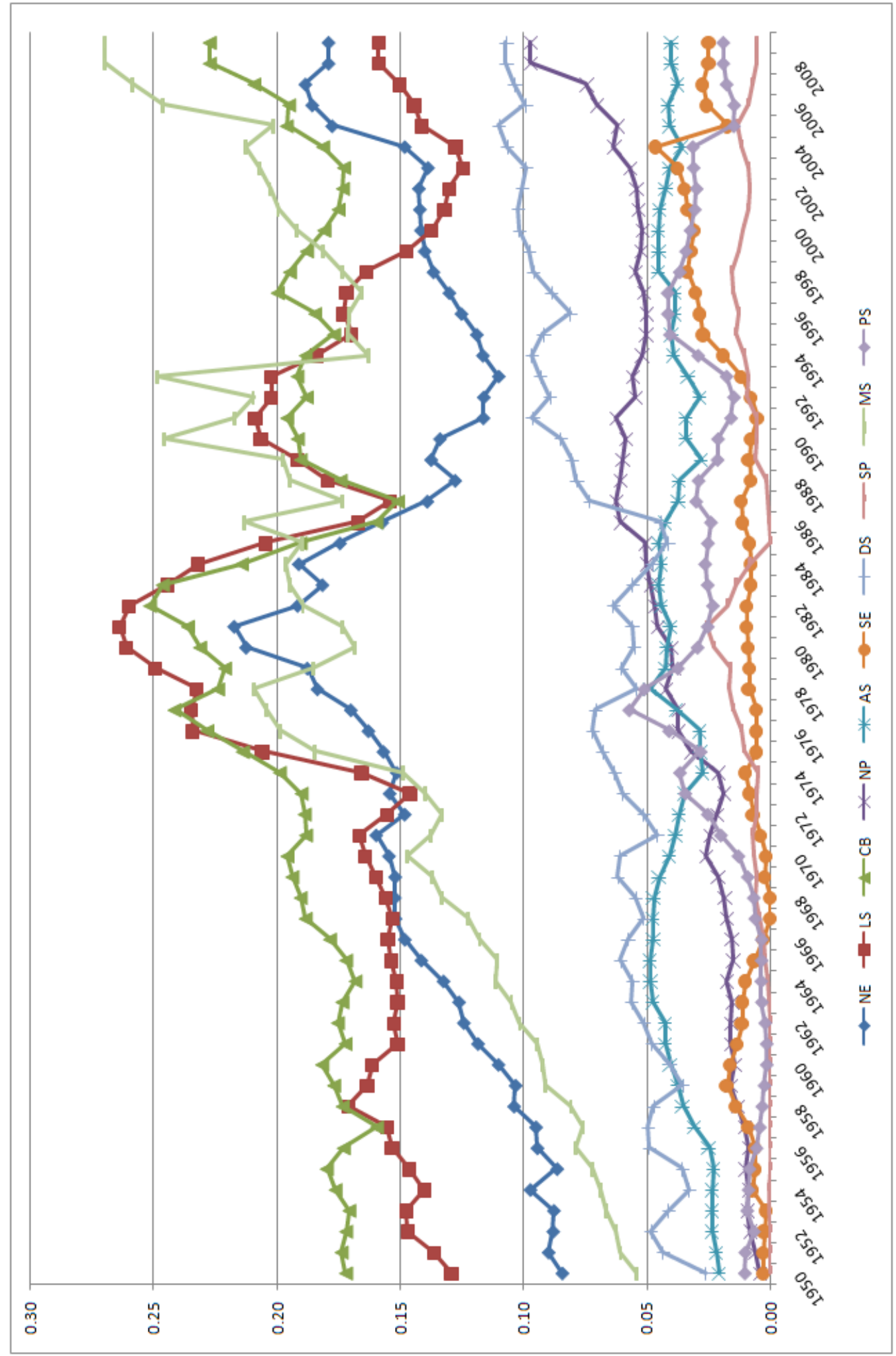


Figure 4: Information inequality regional decompositions (population prior)

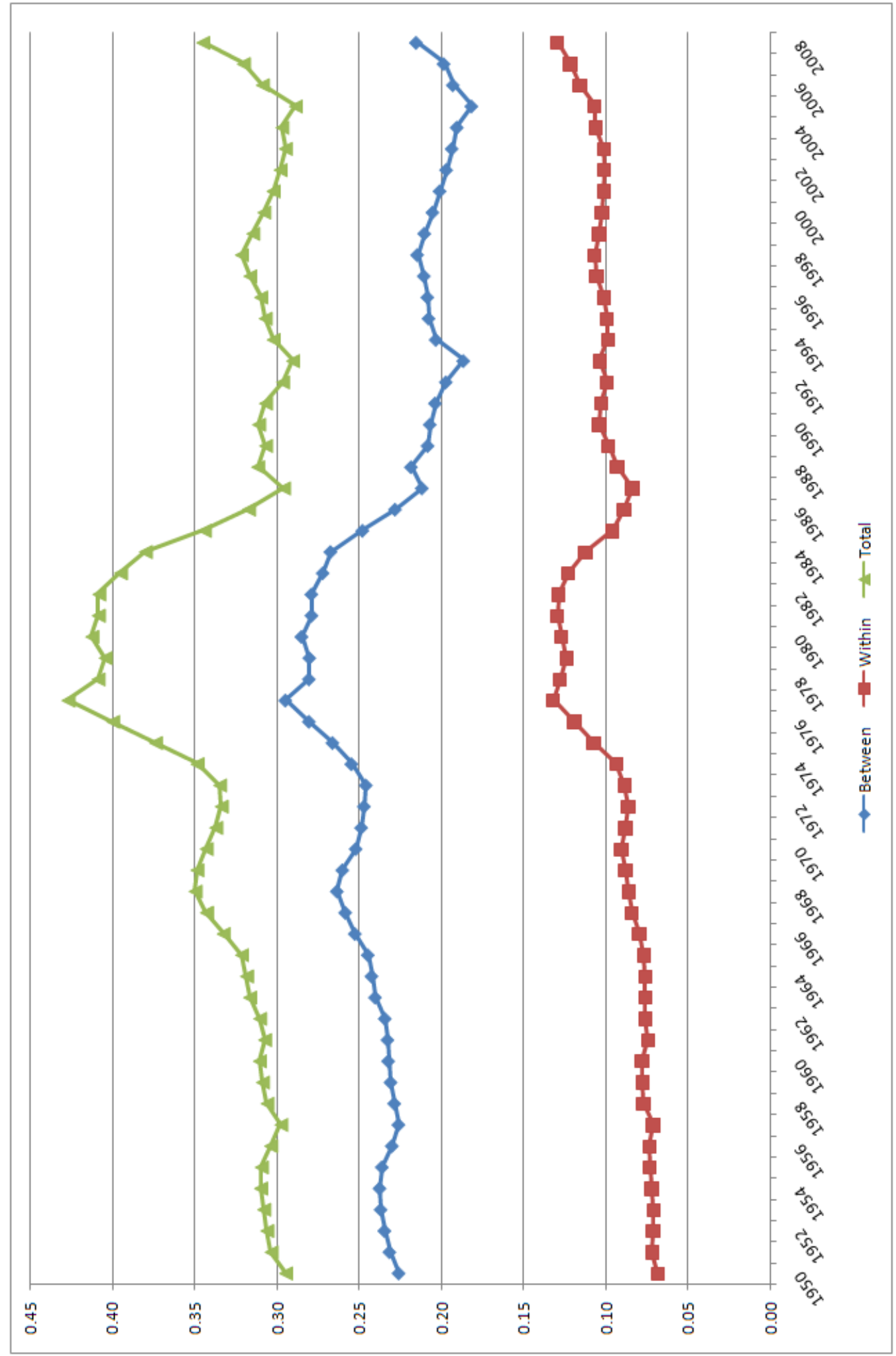


Figure 5: Information inequality within regions (net value added prior)

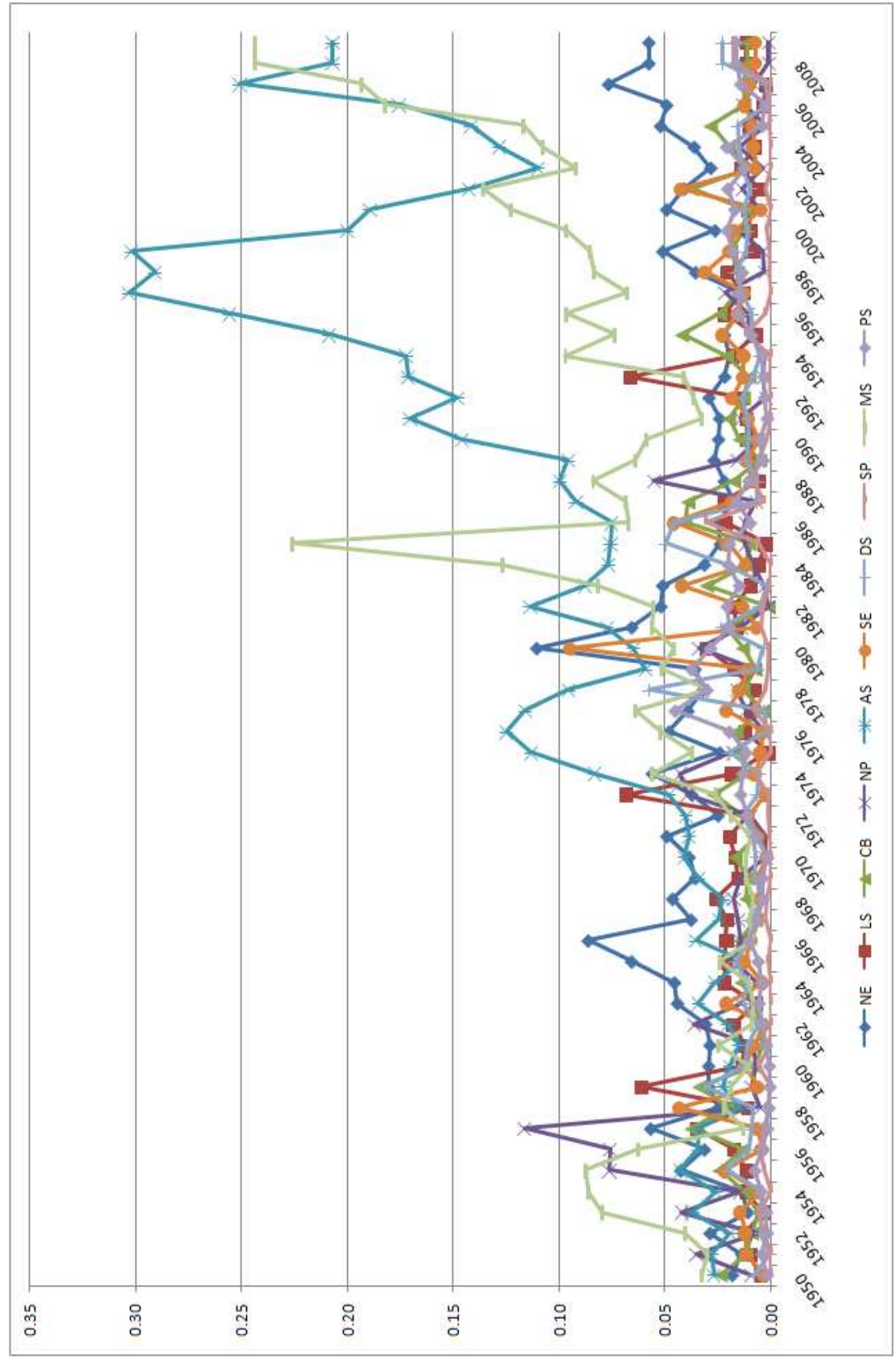


Figure 6: Information inequality regional decompositions (net value added prior)

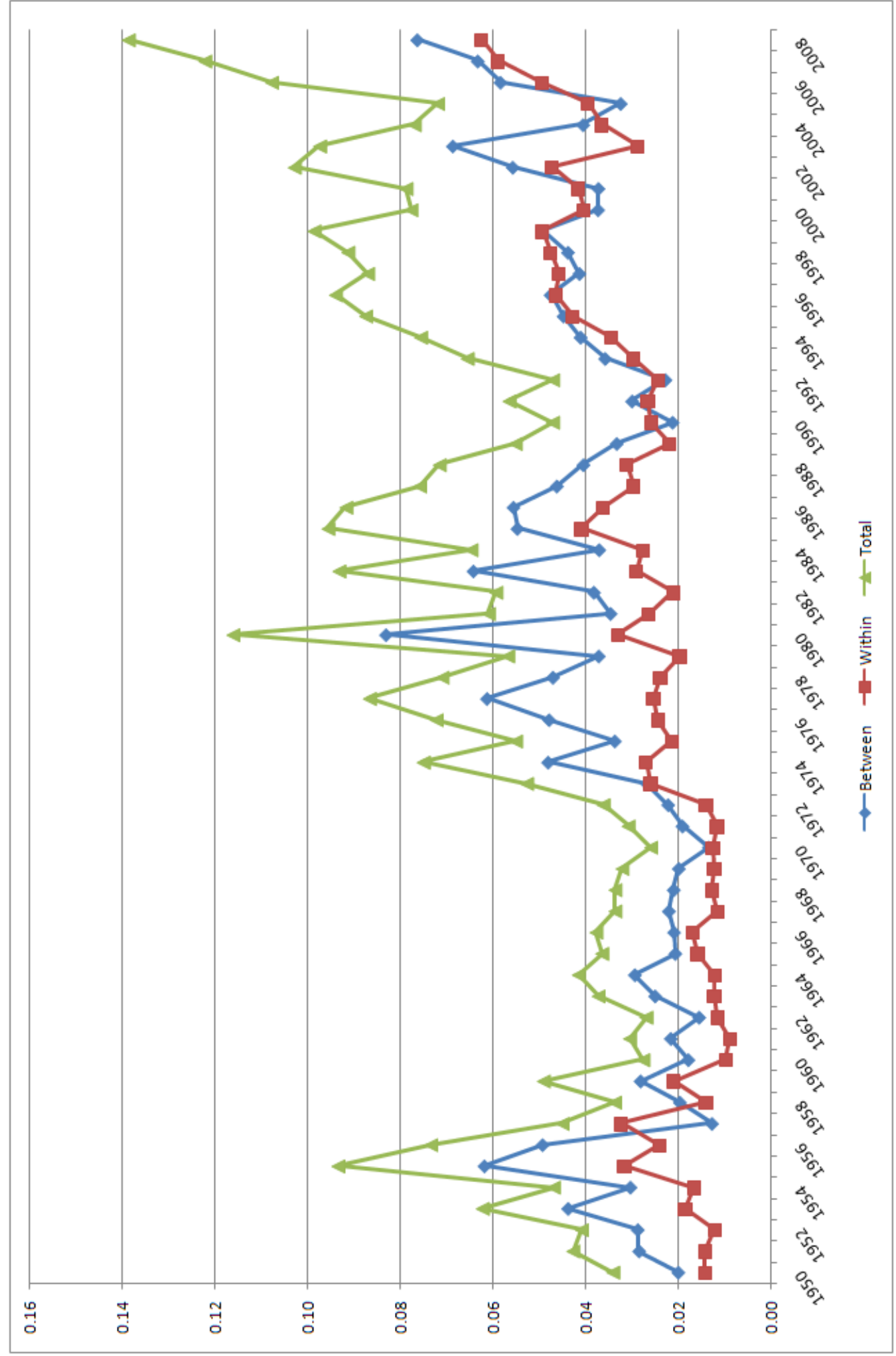

